\title{
The Moderating Effects of Financial Broad-scope Trust on Consumer Knowledge, Cognitive Effort, and Financial Healthiness
}

\author{
Hansen, Torben
}

Document Version

Accepted author manuscript

Published in:

Journal of Consumer Behaviour

DOI:

$10.1002 / \mathrm{cb} .1621$

Publication date:

2017

License

Unspecified

Citation for published version (APA):

Hansen, T. (2017). The Moderating Effects of Financial Broad-scope Trust on Consumer Knowledge, Cognitive Effort, and Financial Healthiness. Journal of Consumer Behaviour, 16(2), 161-175.

https://doi.org/10.1002/cb.1621

Link to publication in CBS Research Portal

\section{General rights}

Copyright and moral rights for the publications made accessible in the public portal are retained by the authors and/or other copyright owners and it is a condition of accessing publications that users recognise and abide by the legal requirements associated with these rights.

\section{Take down policy}

If you believe that this document breaches copyright please contact us (research.lib@cbs.dk) providing details, and we will remove access to the work immediately and investigate your claim.

Download date: 26. Apr. 2023 


\section{The Moderating Effects of Financial Broad-scope Trust on Consumer Knowledge, Cognitive Effort, and Financial Healthiness Torben Hansen}

Journal article (Accepted version)

This is the peer reviewed version of the following article: The Moderating Effects of Financial Broad-scope Trust on Consumer Knowledge, Cognitive Effort, and Financial Healthiness. / Hansen, Torben. In: Journal of Consumer Behaviour, Vol. 16, No. 2, 2017, p. 161-175, which has been published in final form at http://dx.doi.org/10.1002/cb.1621.

This article may be used for non-commercial purposes in accordance with Wiley Terms and Conditions for Self-Archiving.

Uploaded to Research@CBS: June 2017 
The Moderating Effects of Financial Broad-scope trust on

\author{
Consumer Knowledge, Cognitive Effort, and Financial Healthiness ${ }^{1}$
}

By

Torben Hansen, Professor, Ph.D.

Department of Marketing, Copenhagen Business School,

Solbjerg Plads 3, 2000 Frederiksberg,

Denmark,

Tel. +4538152100,

Email: th.marktg@cbs.dk

ACKNOWLEDGEMENT: The data for this study were collected in collaboration with the Danish Money and Pension Panel.

\title{
BIOGRAPHICAL NOTE
}

Torben Hansen, $\mathrm{PhD}$, is a professor at the Department of Marketing, Copenhagen Business School (CBS). He is the chairman of the Consumer Research Group at CBS and the former chairman of the Danish Money and Pension Panel. His main fields of research are consumer behaviour and marketing research methods. He has authored several books, and his papers have appeared in various academic journals. Also, he is co-authoring the European edition of the classic Marketing Management. He has worked as a consultant for various organisations. 


\section{The Moderating Effects of Financial Broad-scope trust on Consumer Knowledge, Cognitive Effort, and Financial Healthiness}

Substantial research results suggest the global financial crisis has negatively affected consumers' trust in financial service providers. Notably, trust not only relates to consumer trust in individual companies but also relates to the broader business context in which consumers may plan and carry out their financial behaviour. This latter form of trust can be referred to as 'broad-scope' trust (BST). BST is especially important in a society context since lack of BST may reduce financial market dynamism, competition, and productivity. Consequently, financial service providers assume an important social responsibility in order to develop BST. Unfortunately, not much is known about the interplay between BST and consumer financial behaviour. Based on two surveys comprising 1,155 bank consumers and 756 mutual fund investors, respectively, this study investigates the moderating influence of BST on relations between knowledge, cognitive effort, and financial healthiness and also examines the direct influence of BST on cognitive effort and financial healthiness. The results indicate that BST negatively moderates relations between knowledge and financial healthiness and between cognitive effort and financial healthiness. In addition, it is demonstrated that BST negatively influences cognitive effort and positively influences financial healthiness. Our results demonstrate the importance of developing BST as it may ease the burdens put on consumers' financial knowledge and processing capabilities, which in turn may facilitate their financial well-being.

Key words: Broad-scope trust, financial behaviour, knowledge, cognitive effort, financial healthiness 


\section{The Moderating Effects of Financial Broad-scope trust on Consumer Knowledge, Cognitive Effort, and Financial Healthiness}

\section{INTRODUCTION}

Trust has long been regarded as one of the most critical variables for developing and maintaining well-functioning markets (Eisingerich and Bell 2007; Morgan and Hunt 1994;

Selnes and Sallis 2003). While there is general agreement that the financial crisis has affected many dimensions of the financial landscape (Bologna 2015), the financial crisis has in particular elevated the focus on consumer trust in financial services (e.g., Sapienza and Zingales 2012; Jizi, Salama, Dixon, and Stratling 2014; Jansen, Mosch, and Cruijsen 2014). Financial trust is also important from a welfare perspective since trust is generally believed to be positively correlated with economic growth (Horváth 2012; Gur 2015; Zak and Knack 2001), and it is therefore in the interest of societies that financial consumers have trust in financial institutions. Moreover, poor functioning financial markets may especially put pressure on vulnerable consumers, which ultimately may lead to reduced financial healthiness (Brennan and Coppack 2008; Aspara, Chakravarti, and Hoffmann 2015). Thus, financial service providers face a social responsibility in contributing to the development of trust in the consumer financial marketplace (Harjoto and Jo 2015; The European Commission 2010).

Notably, trust not only relates to customer trust in individual companies. Trust also relates to the broader business context in which consumers may plan and carry out their financial behaviour, which can be conceptualized as 'broad-scope trust' (BST) (Grayson, Johnson, and Chen 2008). More specifically, BST can be defined as the expectation held by the consumer that companies within a certain business type are generally dependable and can be relied on to deliver on their promises (Hansen 2012a). Despite the well-recognized 
significance of trust in consumer financial behaviour, only few previous studies (i.e., Grayson, Johnson, and Chen 2008; Hansen, 2012a, 2012b, Hansen 2014) have investigated the influence of BST on financial consumer behaviour. However, while past research has considered the direct and indirect influence of BST on relationship satisfaction and trust, no research has examined whether BST may influence relationships between consumer financial knowledge, cognitive effort and financial healthiness. This is unfortunate since past research on decision making has suggested that knowledge and cognitive effort are key constructs in explaining consumer decision behaviour (Todd and Benbasat 1994; Hansen 2012a) and since some financial consumers may have limited financial knowledge and processing capabilities (Oehler and Kohlert 2009); thus being especially vulnerable to financial market conditions. This research seeks to address this shortcoming in the literature by investigating moderating effects of BST on consumer financial behaviour and healthiness. Specifically, we take an ability-effort approach in our study. The ability-effort approach holds the basic premise that the quality of consumer actions is influenced by ability factors such as consumer knowledge and cognitive effort (Alba and Hutchinson 1987, 2000; Alba and Marmorstein 1987). In this study, we demonstrate that consumers may benefit from BST in order to reduce cognitive effort and to improve their financial healthiness. We also show that BST negatively moderates the relations between knowledge and financial healthiness and between cognitive effort and financial healthiness, respectively. The contribution of this study to the consumer behaviour and marketing literature is twofold. Our study provides substantive insights into how BST may influence and moderate relationships between consumer choice and outcome variables. Moreover, we demonstrate that a detailed understanding of the interplay between BST and cognitive effort, knowledge, and financial healthiness, respectively, may be a crucial key for creating well-functioning financial consumer decision environments. 
Our study is based on two surveys. Survey 1 comprises 1,155 bank consumers, whereas survey 2 comprises 756 mutual fund investors. Trust is likely to be especially important in consumer financial behaviour because financial companies have an implicit responsibility for the management of their customers' funds and the nature of financial advice supplied (Jizi, Salama, Dixon and Stratling 2014; Harrison 2003). Moreover, financial services are high in credence properties since even in the usage situation they can often not be evaluated by the customer because of their long-term nature (Darby and Karni 1973) and because customers' may lack the competencies to confidently evaluate the financial consequences of the services (N'Goala 2007). The remainder of the paper is organized as follows. First, the theoretical framework and hypotheses are introduced followed by a review of the methods used to test the hypotheses. Next, the results are presented. Finally, the implications of the findings are discussed and suggestions for future research are provided.

\section{THEORETICAL FRAMEWORK AND RESEARCH HYPOTHESES}

Consumer researchers have long recognized that consumer knowledge and effort is central to understanding consumer behaviour (Alba and Marmorstein 1987; Park, Mothersbaugh, and Feick 1994). Specifically, cognitive effort and the quality of consumer actions are inherent in the effort-accuracy framework of cognition proposed by Payne (1982). According to this framework the primary objectives of a decision maker are to maximize the quality of her/his actions (accuracy) and to minimize cognitive effort. Cognitive effort is the amount of cognitive resources - including perception, memory, and judgment - devoted to a particular cognitive process or activity and is believed to vary with individual characteristics (knowledge, practices) and task demands (complexity of the task) (Cooper-Martin 1994; Garbarino and Edell 1997). However, because consumer objectives concerning use of resources and outcome quality may conflict, compromises are often made between the desire 
to maximize action quality and the desire to minimize cognitive effort (Bettman, Luce, and Payne 1998). Basically, the quality of consumer actions and cognitive effort can either be studied as processes (i.e., the decision strategies used to accomplish choices and actions and cognitive effort goals) or outcomes (Paquette and Kida 1988). By focusing on the amount of cognitive effort expended and on the quality of the behaviour carried out, this study takes an outcome approach.

More cognitive effort is generally believed to lead to higher action quality (Taylor 2009), although this relation may be influenced by ability such that a highly knowledgeable person may attain action quality with relatively less cognitive effort (Kuo, Chu, Hsu, and Hsieh 2004). Drawing on previous research concerning consumer knowledge, effort, and consumer action quality, a baseline model is initially developed (in the following referred to as the 'KCFB baseline model') comprising the constructs knowledge (K), cognitive effort (C), and financial healthiness $(\mathrm{F})$ and the expected relationships between these constructs. The baseline model also comprises BST (B) and its expected direct relationship on cognitive effort and financial healthiness, respectively (Figure 1). Notably, the KCFB baseline model is then used as a basis for modelling the moderating effects of BST on the relationships included in the KCFB baseline model.

\section{Insert Figure 1 about here}

In the baseline model we expect consumer knowledge to positively influence both cognitive effort and financial healthiness. Our expectations are based on research suggesting that knowledge encourages cognitive effort by facilitating the learning of new information (Brucks 1985), and that knowledgeable consumers acquire and retain more information than less knowledgeable consumers (Jayanti and Burns 1998; Lee and Huh 2008). Also, as noted 
by Brucks (1985) knowledge of product attributes may allow the consumer to formulate more questions. In a series of studies Hogarth and Hilgert (2002) and Hilgert, Hogarth, and Beverly (2003) found that financially knowledgeable consumers are more likely to behave in financially responsible ways. The survey results obtained by Perry and Morris (2005) support this notion. Also, as discussed above, cognitive effort is expected to positively influence financial healthiness. In the baseline model, we use the term 'financial healthiness' to describe the quality of consumer financial behaviour. In line with Joo and Grable (2004) and Perry and Morris (2005) we conceptualize financial healthiness as the extent to which the customer exhibits positive financial behaviours, such as paying credit card bills in full each month and avoiding financial troubles caused by not having enough money.

While different forms of trust such as network trust, (inter-)personal trust, and systemic or institutional trust are largely recognized in the literature (e.g., Roth 2009; Beugelsdijk, de Groot, and van Schaikz 2004), previous consumer research has mainly focused on interpersonal trust and has most often investigated just a single, or a few trust types, when examining the role of trust in the consumer marketplace. For instance, the relationship marketing literature (e.g., Regó, Morgan, and Fornell 2013; Hunt, Arnett, and Madhavaram 2006) has focused especially on consumer trust in individual sellers with the purpose of understanding consumer commitment, loyalty, and satisfaction, among other factors. Another stream of research has focused on understanding consumer trust in their knowledge and in their ability to carry out reasonable decisions in the marketplace (e.g., Hansen and Thomsen 2013). However, with a few exceptions (e.g., Grayson, Johnson, and Chen 2008; Hansen 2012a; Hansen 2012b; Hansen 2014) consumer trust in the broader business context (i.e., BST) has received very little attention. BST can be regarded as 'formal' or 'informal'. Formal BST is the belief that proper impersonal structures are in place to enable one to anticipate a successful future endeavour (McKnight, Cummings, and 
Chervany 1998). Formal BST is also referred to as 'system trust' thereby underlining that it relates to the customer's views regarding the formalized regulation of a particular activity system (Grayson, Johnson, and Chen 2008). Informal trust (also referred to as 'generalized trust') (Humphrey and Schmitz 1996) concerns whether the entities in a system can be trusted, regardless of sector or context. People who have informal trust expect system entities to function as they "should" (Muhlberger 2003). In this study, informal trust is considered. This is because informal trust is more directly related to the behaviour of companies than formal trust, which also concerns trust in legal rules and public authorities.

In the baseline model we also expect BST to positively influence both cognitive effort and financial healthiness. Consumer choice theory suggests that consumers have limited cognitive resources and allocate them judiciously (Payne 1982; Garbarino and Edell 1997). Because of this resource limitation cognitive effort can be seen as costly leading consumers to expend only the effort necessary to make a satisfactory, rather than optimal, decision (Fiske and Taylor 1991). Thus, cognitive effort can be both beneficial - as it may lead to a successful resolution and reduction of choice uncertainty - and costly, and may even lead to negative affect (Gabarino and Edell 1997). However, according to functionalism, the functioning of financial markets and the reduction of risk and complexity do not stand and fall by the individual consumer or with the financial service provider with which one communicates and trusts (Jalava 2006; Parsons 1951, 1967; Dixon and Wilkinson 1989). The functionalist perspective holds that in all social systems there are a number of functional prerequisites - such as allocation and performance - that must be met if the system is to function effectively and to survive. All roles must be filled and according to the functionalist perspective they will be filled by those best able to perform them. In order to accomplish this all complex societies need some mechanism that reduces uncertainty and ensures effective role allocation and performance. The more complex a society becomes through functional 
differentiation, the better it is able to reduce the complexity and uncertainty of the environment by managing interdependencies (Jalava 2006). A change of the behaviour of one part of the social system therefore means that other parties of the system may need to modify their behaviour. Specifically, if BST is low it means that consumers cannot just rely on trust in a particular service provider to reduce the complexity and uncertainty they are faced with when choosing among various services - and vice versa when BST is high. Hence, according to functionalist theory the consumer therefore needs to modify her/his behaviour (Dixon and Wilkinson, 1989) in order to reduce the reliance on BST. When faced with such circumstances, consumer choice theory suggests that a consumer will tend to more thoroughly evaluate the more specific consequences both of choosing one alternative and of foregoing the other (Shiu, Walsh, Hassan, and Shaw, 2011). Hence, the consumer could be expected to allocate more resources to the evaluation of services offered in the financial marketplace. Hence, we expect in the baseline model that BST has a negative influence on cognitive effort.

The processes and structures that are established within a society, or a community, may act as authoritative guidelines for social behaviour (Scott 2004; Collin et al. 2009; Lubatkin, Lane, Collin, and Very 2005). Social behaviour needs to be legitimized by the rules, ethics, and norms that exist in the broader social environment (Scott 2004; Vallaster, Lindgreen, and Maon 2012). The normative mechanism can, however, be expanded to include all normative pressures on individuals (Collin et al. 2009). When facing normative pressure consumers may internalize the viewpoints and norms, making them evident instead of subject to choice. This implies that institutions not only may create legitimacy, but that they also may be influential on the very shaping of consumers preferences and behaviour (Lubatkin et al. 2005). If trust is common within financial institutions, meaning that businesses are generally honest and can be relied on to keep their promises, it should be 
expected to legitimate and encourage the development of similar positive financial behaviours among their customers (e.g., paying bills on time, etc.), and vice versa when BST is low. This suggests the existence of a positive relationship between BST and financial healthiness. Notably, the expected positive relationship is also consistent with the concept of reciprocity (e.g., Chan and Li 2010), which in the present context suggests that if consumers believe a business will act (or has acted) trustful toward them then they will feel a sense of duty toward the business (e.g., by paying a bill on time). In sum, we expect in the baseline model that BST has a positive influence on financial healthiness.

\section{Hypothesized model relationships}

The specification of the hypothesized moderating effects of BST on the relationships in the KCFB model draws on attribution theory. Specifically, it is suggested that BST will negatively moderate the relationships in the KCFB model. Attribution theory describes consumers' evaluation of causality on the basis of different situational contexts (Weiner 1985, 1986; Fiske and Taylor 1991; Tomlinson and Mayer 2009). Weiner (1986) suggests that an individual's perception of an outcome leads to a general emotional reaction of pleasure, or displeasure, which causes the individual to identify the outcome's cause. Kelley (1967) has conceptualized this as the "process by which an individual interprets events as being caused by a particular part of an environment" (p. 193). Weiner (1985) states that the causes of all outcomes can be decomposed into a set of points on three orthogonal continua, or causal dimensions. These continua are (a) locus - the prior outcome's causal agent relative to the decision maker; (b) stability, stable to unstable - the likelihood that a prior outcome's causal agent will persist in the future; and (c) controllability, controllable to uncontrollable the decision maker's degree of influence over the causal agent. Attribution research can be useful in exploring how consumers explain their financial experiences. Locus of causality 
relates to the location attributed to the cause of an outcome. It could be an internal position (the cause is located in the consumer her-/himself or in one of her/his decisions), external (located in the company that offers the service), or situational (located in environmental effects) (Oliver 1993; Ryu, Park, and Feick 2006). In that respect, consumers will distinguish between causes that are internal, external, and situational. Locus of causality is particularly relevant in the present study because it explicitly distinguishes between situational causes (i.e., BST) and causes that are more directly related to the individual consumer. Attribution theory suggests that consumers will try to understand success or failure in terms of locus of causality indicating that BST may be taken into account by consumers when attributing the cause of their experiences (Cox and Walker 1997).

Attribution theory predicts that consumers are more likely to attribute outcomes to their own effort and knowledge when they make lower situational attributions towards a positive experience (Weiner 1986). Hence, financial suppliers are viewed as more responsible for the positive experience when external attributions are made, whereas financial suppliers are perceived to be less responsible for the positive experience when internal attributions are made. Consistent with this suggestion, empirical findings concerning the behaviours of team members also suggest that if an individual is deemed not to be responsible for her/his unfavourable behaviour (i.e., the unfavourable behaviour can be attributed to situational effects) then prosocial behavioural responses from peers are more likely (Weiner, 1985). Drawing on such insights, it is predicted that in an environment where BST is low, consumers should be expected to be more likely to attribute negative experiences to situational causes and less likely to attribute negative experiences to internal causes (i.e., poor knowledge and/or cognitive effort) compared with environments where BST is high. In a similar vein, when BST is low consumers should be expected to be less likely to attribute positive experiences to situational causes and more likely to attribute positive experiences to 
internal causes (i.e., good knowledge and/or cognitive effort) compared with environments where BST is high.

Specifically, in trying to assess the causes for their level of cognitive effort and financial healthiness, consumers may evaluate their experiences in the light of the perceived trustworthiness of financial companies. In incidents where BST is low, attribution theory suggests that consumers would be more inclined to attribute outcome experiences to internal causes; and vice versa when BST is high. Thus, it is expected that BST would negatively moderate the relationships between knowledge and cognitive effort and between cognitive effort and financial healthiness, respectively. It is also argued that BST should be expected to negatively moderate the relationship between knowledge and financial healthiness. This is because when BST is low, the consumer should be expected to be more likely to attribute positive outcomes to financial knowledge than to a situational cause; and vice versa when BST is high. Notably, the potential fulfilment of these propositions is in particular important to financially vulnerable consumers who may face severe difficulties in improving individual causes (i.e., financial knowledge and cognitive effort) for their financial healthiness when needed; that is, when BST is low.

In sum, the following hypotheses are proposed.

H1: The influence of knowledge on cognitive effort is negatively moderated by BST, such that knowledge has a greater positive effect on cognitive effort when BST is low compared to high.

$\mathrm{H} 2$ : The influence of knowledge on financial healthiness is negatively moderated by BST, such that knowledge has a greater positive effect on financial healthiness when BST is low compared to high. 
H3: The influence of cognitive effort on financial healthiness is negatively

moderated by BST, such that cognitive effort has a greater positive effect on financial healthiness when BST is low compared to high.

\section{Control variables}

The purpose of this paper is to study the moderating effect of BST on the specified relationships between knowledge, cognitive effort, and financial healthiness, respectively. However, we suggest that a number of variables may be related to the endogenous constructs in the KCFB framework and their effects should therefore be taken into account (e.g., Johansson, Dimofte, and Mazvancheryl 2012). These variables are financial involvement, income, and education. Although the control variables are not the focus of this study, controlling for their effects provides a stronger test of the proposed hypotheses (Greene 2000).

Consistent with past research, financial involvement is defined as the extent to which individuals are personally interested in a range of issues related to financial issues (Moorman and Matulich 1993). Consumers who are highly involved with their financial matters are likely to make a significant effort to process financial information when considering financial matters and may be more inclined to maintain financial healthiness (Mende and van Doorn 2015). Past research suggests that education may facilitate the individual to solve more complex problems and to take on more cognitive effort (Donald 2002) and that income is positively related to both education (Reeh 2007) and financial healthiness (Reeh 2007). 


\section{METHODOLOGY}

\section{Data collection}

Two financial service industries were selected for our study: banks and mutual fund companies with respondents being customers of the services of each company. The use of multiple service industries provides a more robust test of model relationships by allowing greater variability in study constructs (Sirdeshmukh, Singh, and Sabol 2002). For each industry, a two-step procedure was utilized to sample respondents from Capacent Epinion's online panel of approximately 30,000 (Danish) consumers. In the first step, a stratified random sample of 4,590 respondents aged 18+ was drawn from the online panel, reflecting the distribution of gender, age, and educational level in the population (aged 18+) as a whole. In the second step, these 4,590 respondents were contacted by email, and asked to respond to the screening question: "Have you recently been in contact with your current (main) bank/mutual fund company?" (Yes/No/Not currently engaged with a bank/a mutual fund company) to ensure that only ongoing relationships were included in the sample.

In the final samples (bank sample, $n=1155$; mutual fund sample, $n=756$ ), 52.3\% (bank sample) and 48.5\% (mutual fund sample), respectively, were women and average age was 46.5 years (bank sample) and 49.3 years (mutual fund sample), respectively, with ranges between $18-85$ in both samples. It was investigated whether the profiles of the study samples deviated from the country population aged $18-85$ on gender and educational level. $\chi^{2}$-tests of difference between sample and population frequencies on each of these criteria produced pvalues >.11 for the bank sample, and p-values of .04 (gender) and .10 (education) for the mutual fund sample. Although women were slightly underrepresented in the mutual fund sample (48.5\% in the sample vs. $50.6 \%$ in the population), the results indicate that the samples to a fair degree reflected the demographic profile of the studied country population. 


\section{Measurements}

Our measurement items were based on prior research, modified to fit the financial service context of this study where relevant. The final items for each construct are summarized in the appendix. Four items based on Tax, Brown, and Chandrashekara (1998) measured BST. Cognitive effort was measured by three items adapted from cognitive effort scale developed by Cooper-Martin (1993). The measurement of cognitive effort related to the last service that the respondent has acquired from her/his main bank/mutual fund company. We focused on specific transactions (instead of just asking respondents to state their general cognitive effort when acquiring the type of financial service in question) in order to enable respondents to more accurately recall their cognitive effort expended. Moreover, focusing on the last completed transaction is consistent with the financial healthiness concept (which deals with current financial behaviour) included in the study. Three items adapted from Kopalle and Lehmann (2001), along with one additional item, measured financial involvement.

In recent years, research has increasingly made a distinction between subjective knowledge, which refers to individuals' perceptions of their own knowledge, and objective knowledge, which refers to absolute knowledge measured against objective standards (Alba and Hutchinson 2000; Klayman, Soll, González-Vallejo, and Barlas 1999; Park, Mothersbaugh, and Feick 1994; Cowley and Mitchell 2003). While past research (e.g., Perry and Morris 2005) has examined self-assessed (subjective) knowledge, no past research known to us has taken into account both consumers' subjective and objective financial knowledge in relation to cognitive effort and financial behaviour. Specifically, the distinction between subjective and objective knowledge is inherent in the knowledge calibration paradigm, which refers to the correspondence between accuracy (objective knowledge) and confidence (subjective knowledge) in knowledge (Hansen and Thomsen 2013; Alba and Hutchinson 2000; Pillai and Goldsmith 2006). The knowledge calibration paradigm states 
that even low levels of objective knowledge can represent a valuable knowledge resource as long as consumers assess it correctly and thus take proper action. In accordance with this notion both consumers' subjective and objective financial knowledge are measured in this study. Objective knowledge was measured using a series of ten financial knowledge items. The items were developed upon a 20-item pool, derived partly upon financial basics, partly from official regulations issued by financial authorities. Six of the items related to both types of financial services and were identical across service industries, whereas four items related to the specific service industry under consideration. All items were exposed to respondents as true/false items. For example, respondents were asked to indicate whether it is true or false that 'Annual Percentage Rate (APR) is an overall indication of how much you pay on a loan only from the perspective of the establishment costs and commission fees.' Subjective knowledge was measured in two ways. First, for each of the ten items, respondents indicated their answer and also indicated their confidence (subjective knowledge) that the answer was correct. We adapted the restricted scale procedure applied by Pillai and Hofacker (2007) and exposed respondents to a scale ranging from $50 \%$ to $100 \%$. Second, we used the three-item subjective knowledge scale provided by Mukherjee and Hoyer (2001). The coefficient alpha for the combined objective and subjective measures was .81, indicating a high degree of internal consistency. Also, a factor analysis of the scores for the objective and subjective measures yielded only one factor with an eigenvalue greater than one with all the scores loading highly on this factor. Since the subjective and objective measures of knowledge are highly related, we combine them into one measure of knowledge since it is more reliable (Cowley and Mitchell 2003). This is consistent with previous research, which has found that the relationship between objective and subjective knowledge is sometimes strong enough to warrant treating them as a single construct (Carlson, Vincent, Hardesty, and Bearden 2009; Cowley and Mitchell 2003). However, we also tested all the hypotheses using just the 
subjective measures and using just the objective measure, respectively. The results for all the hypotheses tests for both of these measures are identical to the results reported in this study suggesting that the results are robust with respect to the knowledge measure used. Financial healthiness was measured using six items adapted from the financial healthiness scale provided by Joo and Grable (2004). In the questionnaire, the items used to measure the study constructs were presented in random order.

\section{RESULTS}

This section presents our results. We begin with a validation of the applied measurement items. We then examine whether common method bias may pose a serious threat to the analysis and interpretation of the data. We conclude with testing our hypothesized model and the hypothesized moderation effects.

\section{Validation of measurements}

Confirmatory factor analysis (CFA) was conducted on the four latent factors and the latent control variable (i.e., financial involvement), with each indicator specified to load on its hypothesized latent factor. Initially, a fully restricted model was estimated holding all correlations and paths invariant across the two datasets. Next, using a chi-square difference test, we investigated whether correlations with significant test statistics varied across subsamples. All of the released correlations failed to enhance model fit suggesting that the investigated correlations did not differ significantly across the two subsamples. Hence, the pooled sample of respondents was used as input for the maximum likelihood estimation procedure using raw data (Gerbing and Anderson 1988). Table 1 summarizes the CFA results.

Insert Table 1 about here 
The measurement model yields a chi-square of 724.52 (d.f.=199, $p<.01$ ). However, the Hoelter(.05) (Hoelter 1983) estimate $(n=455)$ suggests that the lack of absolute fit can be explained by sample size. Thus, since the chi-square test is highly sensitive to sample size (MacCallum and Austin 2000) other fit measures are given greater prominence in evaluating model fit (e.g., Ye, Marinova, and Singh 2007). The root mean square error of approximation $(\mathrm{RMSEA}=.050)$, the comparative fit index $(\mathrm{CFI}=.94)$ and the normed fit index $(\mathrm{NFI}=.93)$ suggest that the measurement model fits the data reasonably well (Bagozzi and Yi 1988). Composite reliability, which represents the shared variance among observed items measuring an underlying construct (Workman, Homburg, and Jensen 2003) was examined. All reliabilities were close to or greater than .80 , indicating good reliability of measured constructs (Bagozzi and Yi 1988). Finally, extracted variance was equal to or greater than .50 for all latent constructs, which satisfies the threshold value recommended by Fornell and Larcker (1981).

In order to investigate discriminant validity the method proposed by Fornell and Larcker (1981) was applied. According to this method, the extracted variance for each individual construct should be greater than the squared correlation (i.e., shared variance) between constructs. An examination of Tables 1 and 2 shows that the extracted variance for each of the constructs exceeds the squared correlation suggesting sufficient discriminant validity.

Insert Table 2 about here

\section{Common method variance}

Initially, a CFA approach to Harmon's one-factor test was used as a diagnostic technique for assessing the extent to which common method bias may pose a serious threat to the analysis and interpretation of the data (Kandemir, Yaprak, and Cavusgil 2006; Ramani and Kumar 
2008). The single latent factor accounting for all the manifest variables yielded a chi-square value of 6888.09 (d.f. $=209, p<.01$ ). A chi-square difference test between the chi-square values of the two models suggested that the fit of the one-factor model was significantly worse than the fit of the four-factor model $\left(\Delta \chi^{2}=6163.57 ; \Delta\right.$ d.f. $\left.=10, p<.01\right)$ indicating that the measurement model was robust to common method variance.

Next, the marker variable test suggested by Lindell and Whitney (2001) was conducted. In accordance herewith, a CMV-marker variable that is theoretically unrelated to at least one of the utilized research scales was used. Specifically, a three-item scale measuring customers' 'propensity to use the web when searching for financial information' $(\alpha=.82)$ (see appendix) was chosen. This construct can be considered theoretically unrelated to BST $\left(\mathrm{r}_{x y}=.06\right)$ as it does not relate to the magnitude of information search but merely to the use of a particular search instrument. Next, the correlations among study constructs with the CMV marker partialled out of each correlation were calculated (Table 2). An inspection of Table 2 shows that all significant zero-order correlations (reported below the diagonal) remained significant when adjusted for common method variance (reported above the diagonal) suggesting that the results cannot be accounted for by common method variance (Lindell and Whitney 2001). In summary, based on the results of the conducted tests, common method variance does not appear a problem in this study.

\section{Model and hypotheses testing}

The moderating effects were formed using the residual-centering ((i.e., orthogonalizing), twostep procedure recommended by Little, Bovaird, and Widaman (2006). As an advantage of this procedure, the regression coefficients and standard errors of the first-order effect terms remain unchanged when the corresponding interaction term is entered. First, for each of the two interactions, i.e., interactions involving BST and either knowledge or cognitive effort, 
each of the possible product terms was regressed onto the first-order effect indicators of the two constructs under consideration. Second, for each of these regressions, the residuals were saved and used as indicators of the interaction construct. This method, which is facilitated by the relatively large sample size of this study, is regarded superior to more common path models, because it incorporates measurement error. Accounting for measurement error is beneficial because measurement error in exogenous and endogenous variables can attenuate regression coefficients and induce biased standard errors, respectively (Kaplan 2009). Both the four main effects and the three hypothesized interaction effects were estimated in the model. Since orthogonalizing via residual centering ensures full independence between the product terms and their constituent main effects no correlations were specified between the interactions and their corresponding main effect latent variables when estimating the hypothesized model.

The hypothesized model (i.e., the model including the moderation effects) was fitted simultaneously to the bank and mutual fund services samples using multiple-group latent variable structural equation modelling (SEM) analysis. By using multiple-group analysis we also take into account the possibility that the control variables may not have similar relationships with the endogenous model variables in both samples. The model chi-square statistic was 6180.55 (d.f.=2383, $p<.01$ ), indicating that the model fails to fit in an absolute sense. However, since the $\chi^{2}$-test is very powerful when $n$ is large, even a good fitting model (i.e., a model with just small discrepancies between observed and predicted covariances) could be rejected. The more robust fit indexes $(\mathrm{CFI}=.92 ; \mathrm{NFI}=.90 ; \mathrm{RMSEA}=.076)$ indicated an acceptable model fit. In addition, the NNFI, which is thought to be sensitive to both explanation and parsimony, equals .90 , suggesting that the model shows an appropriate balance between these competing goals. The $\mathrm{R}^{2}$-values were as follows. $\mathrm{R}^{2}$ (cognitive effort): 
bank services $=.05$, mutual fund services $=.05 . \mathrm{R}^{2}$ (financial healthiness): bank services $=.14$, mutual fund services=.11.

While this study takes a consumer ability-effort approach, this approach usually considers constructs that can be associated with the individual consumer (see e.g., Hansen and Thomsen 2013). Hence, by including a contextual construct (i.e., BST) we modify the ability-effort approach and we therefore wanted to consider whether the inclusion of BST improves model fit. To test this issue, the KCFB baseline model (omitting any relationships involving BST, but retaining all other relationships), was estimated. Compared with the proposed model the results suggest that baseline model had inferior fit statistics: $\chi^{2}=6259.47$, d.f. $=2393, p<.01 ; \mathrm{CFI}=.89 ; \mathrm{NFI}=.89 ; \mathrm{RMSEA}=.085 ; \mathrm{NNFI}=.88 ; \Delta \chi^{2}=78.92, \Delta$ d.f. $=10, p<.01$. This indicates that including BST in the analysis is an improvement to model fit and that the hypothesized model is a reasonable fit to the data.

Table 3 displays the estimated coefficients from the multiple-group SEM analysis.

Insert Table 3 about here

The results indicate that all relationships in the KCFB model are significant and in the expected directions. Knowledge positively influenced cognitive effort (bank services: $\beta=.14$, $p<.01$; mutual fund services: $\beta=.14, p<.01$ ) and financial healthiness (bank services: $\beta=.20$, $p<.01$; mutual fund services: $\beta=.20, p<.01)$. Also, cognitive effort had a positive influence on financial healthiness (bank services: $\beta=.10, p<.01$; mutual fund services: $\beta=.10, p<.01$ ). The results also suggest that BST negatively influenced cognitive effort (bank services: $\beta=-.09$, $p=.04$; mutual fund services: $\beta=-.09, p=.04)$ and positively influenced financial healthiness (bank services: $\beta=.21, p<.01$; mutual fund services: $\beta=.20, p<.01$ ). 
In contrast to the expectation that a negative moderating effect would occur, BST did not moderate the relation between knowledge and cognitive effort (bank services: $\beta=-.05$, $p=.33$; mutual fund services: $\beta=-.07, p=.20$ ), although the coefficients were in the expected direction. Thus, H1 was rejected. However, we also obtained two significant moderating effects. First, BST negatively moderated the relation between knowledge and financial healthiness (bank services: $\beta=-.12, p=.05$; mutual fund services: $\beta=-.14, p=.04$ ). This provides support to H2. Second, BST negatively moderated the relation between cognitive effort and financial healthiness (bank services: $\beta=-.12, p=.04$; mutual fund services: $\beta=-.11, p=.05$ ). Thus, H3 was supported. The significant moderating (interaction) effects are displayed in Figures 2 and 3.

Insert Figures 2 and 3 about here

When BST is low, consumers with high knowledge (upper lines) exhibit a significantly $(p<.01)$ better financial healthiness than consumers with low knowledge (lower lines). When BST is high, no difference in financial healthiness was found between levels of knowledge (Figure 2). In a similar vein, When BST is low, consumers with high cognitive effort (upper lines) exhibit a significantly $(p<.01)$ better financial healthiness than consumers with low cognitive effort (lower lines). When BST is high, no difference in financial healthiness was found between levels of knowledge (Figure 3). These results are consistent across both financial industries. This means that consumers low in knowledge/cognitive effort benefit when BST is high, while consumers with high knowledge/cognitive effort no longer exhibit better financial healthiness than consumers with low knowledge/cognitive effort.

Of the control variables, financial involvement had a positive influence on cognitive effort for both bank and mutual fund services (bank services: $\beta=.18, p<.01$; mutual fund services: $\beta=.18, p<.01)$ and on financial healthiness for mutual fund services $(\beta=.10, p=.05)$. 
Moreover, income had a positive influence on cognitive effort for bank services $(\beta=.07$, $p=.05$ ) and on financial healthiness for both bank and mutual fund services (bank services: $\beta=.18, p<.01$; mutual fund services: $\beta=.22, p<.01)$.

The specified KCFB baseline model suggests that cognitive effort partially mediates the relationship between knowledge and financial healthiness and that this mediation relationship is moderated by BST. When BST is low, the results revealed that knowledge positively affects financial healthiness (banks: $\beta=.26, p<.01$; mutual funds: $\beta=.27, p<.01$ ), whereas there was no direct link between knowledge and financial healthiness when BST is high (banks: $\beta=.08, p=.52$; mutual funds: $\beta=.08, p=.48$ ). This suggests that partial mediation can potentially be supported when BST is low, whereas only full mediation may potentially occur when BST is high (Kenny 2009). To test these underlying processes, we used biascorrected bootstrapping to generate a 95\% confidence interval around the indirect effect of cognitive effort, where mediation occurs if the confidence interval excludes zero (Etkin, Evangelidis, and Aaker 2015). When BST is low, the indirect effect of knowledge on financial healthiness through cognitive effort is significant (banks: $\beta=.04,95 \%$ confidence interval $[\mathrm{Cl}]=[.01, .08]$; mutual funds: $\beta=.04,95 \%$ confidence interval $[\mathrm{Cl}]=[.01, .09])$, whereas the indirect effect was not significant when BST is high (banks: $\beta=.01,95 \%$ confidence interval $[\mathrm{Cl}]=[-.03, .05]$; mutual funds: $\beta=.01,95 \%$ confidence interval $[\mathrm{Cl}]=[-$ $.04, .05])$. This means that the relationship between knowledge and financial healthiness is partially mediated by cognitive effort when BST is low, whereas no mediation takes place when BST is high. In sum, these results are in line with our expectation that the direct effect of knowledge on financial healthiness and the indirect effect of knowledge on financial healthiness through cognitive effort are both lower when BST is high versus low. 


\section{DISCUSSION}

The present research points to the importance of BST in understanding consumer financial behaviour. We investigated the direct influence of BST on consumer financial cognitive effort and financial behaviour and the moderating influence of BST on relations between consumer knowledge, cognitive effort, and financial healthiness. The results of our studies provide evidence that the explanation and understanding of relations between consumer knowledge, cognitive effort, and financial healthiness is significantly enhanced by inclusion of the potential direct and moderating effects of BST. The estimation of the KCFB relations in the framework indicated that the relations between constructs were significant in the expected directions.

Our results suggest that consumers may benefit from BST in order to reduce cognitive effort. Thus, BST facilitates that even consumers with limited information-processing capabilities can potentially deal with complex decision environments (Bettman, Johnson, Luce and Payne 1993). As expected from the baseline model, we also found that BST has a positive direct influence on consumer financial healthiness. Obviously, consumers may vary according to the healthiness of their personal financial behaviour. Since financial companies are dependent on customers to pay their loans and bills they have a greater interest in developing relations with consumers with a healthy financial behaviour than with the opposite. However, since BST is an environmental effect, its positive influence on financial healthiness holds true even for service providers who have not actively participated in improving BST. As a result a free-riding potential may exist. Financial managers may be reluctant to invest in developing BST since all service providers benefit when BST is high. Because it is in the interest of societies that their citizens have healthy financial behaviours this underscores the importance of developing well-functioning financial regulations, which ensures that BST is not undermined by 'free-riding' service providers. 
On a broader perspective, our results strongly suggest that the investigation of customer ability and efforts should not be limited to focusing on constructs associated with the individual consumer, as it is often modelled (e.g., Hansen and Thomsen 2013; Alba and Hutchinson 1987, 2000; Alba and Marmorstein 1987), but should expand into a broader perspective, which also includes contextual variables (such as broad-scope trust). The study also contributes to the explanation of knowledge-effort-behaviour relations in consumer financial markets and points to financial service providers' social responsibility of developing BST, although one moderating effect was not significant. Consistent across the two financial industries investigated, the results indicate that BST negatively moderates the relation between knowledge and financial healthiness and negatively moderates the relation between cognitive effort and financial healthiness. From a public policy perspective these results are both interesting and encouraging. Several research results and financial reports point to the fact that many consumers possess highly limited knowledge about financial products (e.g., OECD 2006; Estelami 2005; Towers Perrin, 2008). This has resulted in the establishment of financial education programmes in many countries and also the Organisation for Economic Co-operation and Development (OECD) prioritizes this issue. As one consequence of this prioritization, OECD has developed the OECD Gateway, which serves as global clearinghouse on financial education, providing access to a comprehensive range of information, data, resources, research and news on financial education issues and programmes around the globe. While OECD (2006) suggests that "individuals will not be able to choose the right savings or investments for themselves, and may be at risk of fraud, if they are not financially literate" (p. 1), it is also acknowledged that "interesting consumers in financial education is no easy task" (p. 4). In light of such notions, the results of the present study stress the importance of BST as it may ease the burdens put on consumers' financial knowledge and processing capabilities in order for them to achieve financial well-being. 
While the results of the present study indicate that knowledge and cognitive effort positively influence financial healthiness, confirming the importance of financial education programs, our results also show that when BST is high (compared to low), the influence of financial knowledge and cognitive effort on financial healthiness diminishes. Hence, the results suggest that BST contributes to the financial well-being of consumers with limited financial knowledge and processing capabilities. Thus, along with educational programs and other initiatives, financial managers, politicians and financial authorities should increasingly be encouraged to deal with the development of BST in order to facilitate consumer financial well-being, especially among financially vulnerable consumers. Notably, this also stresses the importance that financial market authorities continuously monitor consumer trust in the financial marketplace with the aim of seeking a fruitful balance between the mechanisms of various levels of BST.

Although not specifically investigated in the present study, financial authorities and politicians may also focus on the interplay between various types of trust (e.g., trust in individual financial service providers, informal and formal BST, and others) from a consumer financial welfare perspective. The range of choice available to financial consumers has increased dramatically in recent years and growing evidence suggests that in the complex real world many financial consumers rarely have a comprehensive idea of what behaviour may serve their interests in the best way (Sevim, Temizel, and Sayilir 2012; Rotfeld 2008; Lusardi, Mitchell, and Curto 2010). This is important since consumers' bad financial decisions may not only negatively affect their short-term liquidity but may haunt them for years after they are made. In fact, research shows that when the complexity of the information provided exceeds consumers' information processing capacity, the quality of the latter's decision will be affected negatively in a considerable manner (Oehler and Kohlert 2009; Hilgert, Hogarth, and Beverly 2003), which especially may harm those consumers who 
are vulnerable due to their low financial knowledge and/or cognitive effort. In that respect, trust and the various possible interplays between different types of trust may potentially reduce perceived transaction uncertainty and may also serve as heuristic tools, which can be used by consumers to mentally justify their actions (Shiu et al. 2011).

\section{Study limitations and future research}

This study drew on various theories and concepts (i.e., effort-accuracy theory, functionalism, institutional theory, and attribution theory) in order to develop a theoretical understanding of the moderating effects of BST on the KCFB baseline model relations. However, it is not suggested that this study provides a definitive background understanding of the complexity of the proposed relations. Indeed, the coefficient concerning one of the specified hypotheses was not significant, although the coefficient was in the expected direction. Also, this study only considers one aspect of BST (i.e., informal BST) and does not take into account the possible interplay between informal BST and formal BST when estimating the moderating effects of BST on the KCFB baseline model relations. Future research should therefore regard the propositions put forward in this study as starting points for a further understanding of the role of BST on consumer financial behaviour, which is clearly an under-researched topic. In relation hereto, future research could also collect longitudinal data to assess the long-term influences of BST on consumer financial behaviour. Such an investigation could validate the notions that BST negatively influences cognitive effort and positively influences financial healthiness and provide further evidence for the important role of BST as a moderator of the KCFB model relationships. Longitudinal studies would also help understand whether the nature of the effects obtained in this study is indeed long-term.

There are other limitations of this study that should be acknowledged. Although the primary purpose of this research was to investigate possible moderating effects of BST on 
relations between knowledge, cognitive effort, and financial healthiness, and not to explain the variation in the endogenous constructs per se, the relatively low $\mathrm{R}^{2}$-values suggest that there may be other factors, possibly savings and spending plans, social norms, personal values, willingness to take risk, perceived risk (e.g., Yates and Ward 2012; Colquitt et al. 2005; Hauff 2014; Chaudhuri 2010; Granovetter 1985; Paulssen et al. 2011), and others, that may account for the remaining variance in cognitive effort and financial healthiness, respectively. Customers were approached via online surveys; they may behave differently when engaging in specific relationship settings. Thus, although a survey is generally accepted as a means of data collection there is little control over the contextual setting and over the response behaviour of customers. This study concentrated on analyzing the consumer population of one society and in two industries. Although the investigated financial industry types are present in most societies and even though their service offerings are most likely guided by similar financial and economic principles, this could mean that the results may suffer from a lack of generalizability when other countries and/or industries are considered. Future research is also called upon to take into account cultural characteristics such as e.g., the degree of customer uncertainty avoidance, among others. According to Hofstede (2001), uncertainty avoidance reflects a society's tolerance for uncertainty and ambiguity. Since trust may decrease uncertainty, financial customers within uncertainty avoiding societies may put higher emphasis on BST when compared to less uncertainty avoiding societies. Also, this study used perceptive measures, which could be threatened by biased responses. Future research could examine this issue by manipulating BST in an experimental setting. Such an experimental study would also replicate the present cross-sectional survey results in a more controlled laboratory setting, and thus provide stronger evidence for the direction of causality in the proposed research model. The consistency of the findings across two industries and with the theoretical model suggests that the findings will be similar in other services contexts 
(Guo, Arnould, Gruen, and Tang 2013). Indeed, the theoretical underpinnings regarding the interplay between knowledge, cognitive effort, (financial) healthiness, and BST should also hold true for other industries, such as the food market, which also can be characterized by perceived market complexity and demand for trust (e.g., Hansen and Thomsen 2013) and which also focuses on healthiness (in terms of food healthiness).

\section{References}

Alba, J.W., Hutchinson, J.W. 1987. Dimensions of Consumer Expertise. Journal of Consumer Research, 13(March), 411-454.

---, --- 2000. Knowledge Calibration: What Consumers Know and What They Think They Know. Journal of Consumer Research, 27 (September), 123-156.

Alba, J.W., Marmorstein, H. 1987. The Effects of Frequency Knowledge on Consumer Decision Making. Journal of Consumer Research, 14 (June), 14-25.

Anderson, J. C., Gerbing, D.W. 1988. Structural Equation Modelling in Practice: A Review and Recommended Two-Step Approach. Psychological Bulletin, 103(November), 411-423.

Aspara, J., Chakravarti, A., Hoffmann, A. 2015. Focal versus background goals in consumer financial decision-making: Trading off financial returns for self-expression? European Journal of Marketing, 49(7/8), 1114-1138.

Bagozzi, R.P., Yi, Y. (1988). On the Evaluation of Structural Equation Models. Journal of the Academy of Marketing Science, 16(1), 74-94.

Bettman, J.R., Johnson, E.J., Luce, M.F., Payne, J.W. 1993. Correlation, Conflict, and Choice. Journal of Experimental Psychology: Learning, Memory, and Cognition, 19(4), 931-951. 
Beugelsdijk, de Groot, H.L.F., van Schaikz, A.B.T.M. 2004. Trust and economic growth: a robustness analysis. Oxford Economic Papers, 56, 118-134.

Bologna, P. 2015. Structural Funding and Bank Failures - Does Basel 3 Net Stable Funding Ratio Target the Right Problem? Journal of Financial Services Research, 47, 81-113.

Brennan, C., Coppack, M. 2008. Consumer empowerment: global context, UK strategies and vulnerable consumers. International Journal of Consumer Studies, 32, 306-313.

Brucks, M. 1985. The Effects of Product Class Knowledge on Information Search Behavior. Journal of Consumer Research, 12 (June), 1-16.

Carlson, J.P., Vincent, L.H., Hardesty, D.M., Bearden, W.O. 2009. Objective and Subjective Knowledge Relationships: A Quantitative Analysis of Consumer Research Findings. Journal of Consumer Research, 35(February), 864-876.

Chan, K.W. and Li, S.Y. 2010. Understanding consumer-to-consumer interactions in virtual communities: The salience of reciprocity. Journal of Business Research, 63(9-10), 1033-1040.

Chaudhuri, A. 2010. A Macro Analysis of the Relationship of Product Involvement and Information Search: The Role of Risk. Journal of Marketing Theory \& Practice 8(1), 115.

Collin, S-O Y., Tagesson, T., Andersson, A., Cato, J., Hansson, K. 2009. Explaining the choice of accounting standards in municipal corporations: Positive accounting theory and institutional theory as competitive or concurrent theories. Critical Perspectives on Accounting, 20, 141-174.

Colquitt, J.A., Scott, B.A., LePine, J.A. 2007. Trust, trustworthiness, and trust propensity: a meta-analytic test of their unique relationships with risk taking and job performance. Journal of Applied Psychology 92/4, 909-927.

Cooper-Martin, E. 1994. Measures of Cognitive Effort. Marketing Letters, 5 (January), 43- 
56.

Cox, A.E., Walker, O.C. 1997. Reactions to Disappointing Performance in Manufacturer Distributor Relationships: The Role of Escalation and Resource Commitments. Psychology \& Marketing, 14(8), 791-821.

Cowley, E., Mitchell, A.A. 2003. The Moderating Effect of Product Knowledge on the Learning and Organization of Product Information. Journal of Consumer Research, 30(December), 443-454.

Darby, M.R., Karni, E. 1973. Free competition and the optimal amount of fraud. Journal of Law and Economics, 16, 67-86.

Dixon, D.F., Wilkinson, I.F. 1989. An Alternative Paradigm for Marketing Theory. European Journal of Marketing, 23(8), 59-69.

Donald, J.G. 2002. Learning to Think: Disciplinary Perspectives. San Francisco: Jossey Bass. Eisingerich, A.B., Bell, S.J. 2007. Maintaining customer relationships in high credence services. Journal of Services Marketing, 21(4), 253-262.

Estelami, H. 2005. A cross-category examination of consumer price awareness in financial and non-financial services. Journal of Financial Services Marketing, 10(2), 125-139.

Etkin, J., Evangelidis, I., Aaker, J. 2015. Pressed for Time? Goal Conflict Shapes How Time is Perceived, Spent, and Valued. Journal of Marketing Research, LII (June), 394-406.

European Commission. 2010. Corporate social responsibility (CSR). Retrieved from http://ec.europa.eu/enterprise/policies/sustainable-business/corporate-socialresponsibility/index_en.htm.

Fiske, S.T., Taylor, S.E. 1991. Social cognition, (2nd ed.). New York: McGraw-Hill.

Fornell, C. and Larcker, D.F. 1981. Evaluating Structural Equation Models with Unobservable Variables and Measurement Error. Journal of Marketing Research, 
18(1), 39-50.

Garbarino, E.C., Edell, J.A. 1997. Cognitive Effort, Affect, and Choice. Journal of Consumer Research, 24(September), 47-158.

Gerbing, D.W., Anderson, J.C. 1988. An Updated Paradigm for Scale Development Incorporating Unidimensionality and Its Assessment. Journal of Marketing Research, 25(2), 186-192.

Grayson, K., Johnson, D., Chen, D-F. R. (2008). Is Firm Trust Essential in a Trusted Environment? How Trust in the Business Context Influences Customers. Journal of Marketing Research, XLV(April), 241-256.

Greene, W.H. (2000). Econometric Analysis. Upper Saddle River, NJ: Prentice Hall.

Granovetter, M. 1985. Economic action and social structure: the problem of embeddedness. American Journal of Sociology 91(3), 481-510.

Guo, L., Arnould, E.J., Gruen, T.W., ang, C. (2013). Socializing to Co-Produce: Pathways to Consumers' Financial Well-Being. Journal of Service Research, 16(4), $549-563$.

Gur, N. (2015). Trust and the wealth of nations. Progresss in Development Studies, 15(2), $107-124$.

Hansen, T. 2012a. The Moderating Influence of Broad-scope trust on Customer-Seller Relationships. Psychology \& Marketing, 29(5), 350-364.

--- 2012b. Understanding Trust in Financial Services: The Influence of Financial Healthiness, Knowledge, and Satisfaction. Journal of Service Research, 15(3), 280295.

--- 2014. The Role of Trust in Financial Customer-seller Relationships Before and After the Financial Crisis. Journal of Consumer Behaviour, 13(6), 442-452.

---, and Thomsen, T.U. 2013. I Know What I Know, but I Will Probably Fail Anyway: How 
Learned Helplessness Moderates the Knowledge Calibration-Dietary Choice Quality Relationship. Psychology \& Marketing, 30(11), 1008-1028.

Harjoto, M. A., Jo, H. 2015. Legal vs. Normative CSR: Differential Impact on Analyst Dispersion, Stock Return Volatility, Cost of Capital, and Firm Value. Journal of Business Ethics, 128(1), 1-20.

Harrison, T. 2003. Why trust is important in customer relationships and how to achieve it. Journal of Financial Services Marketing, 7(3), 206-209.

Hauff, J.C. 2014. Trust and risk-taking, PhD thesis, School of Business, Economics and Law University of Gothenburg. Available:

https://gupea.ub.gu.se/bitstream/2077/35273/1/gupea_2077_35273_1.pdf

Hilgert, M.A., Hogarth, J.M., Beverly, S 2003. Household Financial Management: The Connection between Knowledge and Behavior. Federal Reserve Bulletin, 89(7), 309322.

Hoelter, J.W. 1983. The analysis of covariance structures: goodness-of-fit indices. Sociological Methods and Research, 11, 325-344.

Hofstede, G. (2001), Culture's consequences. London: Sage Publications.

Hogarth, J.M., Hilgert, M.A. 2002. Financial Knowledge, Experience and Learning Preferences: Preliminary Results from a New Survey on Financial Literacy. Consumer Interests Annual, 48.

Horváth, R. 2012. Does trust promote growth? Journal of Comparative Economics, 41(3), 777-788.

Humphrey, J., Schmitz, H. 1996. Trust and Economic Development. Brighton, UK: Institute of Development Studies, University of Sussex, IDS discussion paper 355.

Hunt, S.D., Arnett, D.B., and Madhavaram, S. (2006). The explanatory foundations of 
relationship marketing theory, Journal of Business \& Industrial Marketing, 21(2), 72-87.

Jalava, J. 2006. Trust as a Decision: The Problems and Functions of Trust in Luhmannian Systems Theory. University of Helsinki, Faculty of Social Sciences, Department of Social Policy Research Reports, 1/2006, 236 pages.

Jansen, D-J., Mosch, R.H.J., Cruijsen, C.A.B. van der 2014. When Does the General Public Lose Trust in Banks? Journal of Financial Services Research, forthcoming.

Jayanti, R. and Burns, A.C. 1998. The antecedents of preventive health care behavior: An empirical study. Academy of Marketing Science, 26(1), 9-15.

Jizi, M.I., Salama, A., Dixon, R., and Stratling, R. 2014. Corporate Governance and Corporate Social Responsibility Disclosure: Evidence from the US Banking Sector. Journal of Business Ethics, 125(4), 601-615

Johansson, J.K., Dimofte, C.V., Mazvancheryl, S.K. 2012. The performance of global brands in the 2008 financial crisis: A test of two brand value measures. International Journal of Research in Marketing, 29(3): 235-245.

Joo, S.-H., Grable, J.E. 2004. An Exploratory Framework of the Determinants of Financial Satisfaction. Journal of Family and Economic Issues, 25(1), 25-50.

Kandemir, D., Yaprak, A., Cavusgil, S.T. 2006. Alliance Orientation: Conceptualization, Measurement, and Impact on Market Performance. Journal of the Academy of Marketing Science, 34(June), 324-340.

Kaplan, D. 2009. Structural Equation Modeling - Foundations and Extension. Advance Quantitative Techniques in the Social Sciences Series, 10, SAGE Publications: Thousand Oaks, California, USA.

Kelley, H.H. 1967. Attribution theory in social psychology. Nebraska Symposium on Motivation, 15, 192-238. 
Klayman, J., Soll, J.B., González-Vallejo, C., Barlas, S. 1999. Overconfidence: It Depends on How, What, and Whom You Ask. Organizational Behavior and Human Decision Processes, 79(September), 216-247.

Kopalle, P.K., Lehmann, D.R. 2001. Strategic Management of Expectations: The Role of Disconfirmation Sensitivity and Perfectionism. Journal of Marketing Research: XXXVIII (August): 386-394.

Kuo, F-Y., Chu, T-H., Hsu, M-H., and Hsieh, H-S. 2004. An Investigation of Effort Accuracy Trade-Off and the Impact of Self-Efficacy on Web Searching Behaviors. Decision Support Systems, 37(June), 331-342.

Lee, C., Huh, J. 2008. Web Site Trust Evaluation as Cognitive Information Processing and the Moderating Role of Involvement and Knowledge. American Academy of Advertising Conference Proceedings, 258-260.

Lindell, M.K., Whitney, D.J. 2001. Accounting for Common Method Variance in Cross Sectional Research Designs, The Journal of Applied Psychology, 86(February), 114121.

Little, T.D., Bovaird, J.A., Widaman, K.F. 2006. On the merits of orthogonalizing powered and interaction terms: Implications for modeling interactions among latent variables. Structural Equation Modeling: A Multidisciplinary Journal, 13(4), 497-519.

Lubatkin, M.H., Lane, P.J., Collin, S.O., Very, P. 2005. Origins of corporate governance in the USA, Sweden and France. Organization Studies, 26(6), 867-888.

Lusardi, A., Mitchell, O.S., Curto, V. (2010). Financial Literacy among the Young. Journal of Consumer Affairs, 44(2), 358-380.

MacCallum, R.C., Austin, J.Y. 2000. Application of Structural Equations Modeling in Psychological Research. Annual Review of Psychology, 51(1), 201-226.

McKnight, H.D., Cummings, L.L., Chervany, N.L. 1998. Initial trust formation in new 
organizational relationships. Academy of Management Review, 23(3), 473-490.

Martin Mende, M., Doorn, J. van 2015. Coproduction of Transformative Services as a Pathway to Improved Consumer Well-Being: Findings From a Longitudinal Study on Financial Counseling. Journal of Service Research, 18(3) 351-368.

Moorman, C., Matulich, E. 1993. A Model of Consumers' Preventive Health Behaviors: The Role of Health Motivation and Health Ability. Journal of Consumer Research, 20(2): 208-228.

Morgan, R.M., Hunt, S.D. 1994. The commitment-trust theory of relationship marketing. Journal of Marketing, 58(3), 20-38.

Muhlberger, P. 2003. Political Trust Vs. Generalized Trust in Political Participation. The American Political Science Association Annual Meeting, Philadelphia, PA, 8/29 to $9 / 2$.

Mukherjee, A., Hoyer, W.D. 2001. The Effect of Novel Attributes on Product Evaluation. Journal of Consumer Research, 28(December), 462-472.

N'Goala, G. 2007. Customer switching resistance (CSR). The effects of perceived equity, trust and relationship commitment. International Journal of Service Industry Management, 18(5), 510-533.

Oehler, A., Kohlert, D. 2009. Financial Advice Giving and Taking_-Where are the Market's Self-healing Powers and a Functioning Legal Framework When We Need Them? Journal of Consumer Policy, 32, 91-116.

Oliver, R.L. 1993. Cognitive, affective and attribute bases of the satisfaction response. Journal of Consumer Research, 20(January), 418-430.

Organisation for Economic Co-operation and Development (OECD) 2006. The Importance of Financial Education. Policy Brief (July), 1-8.

Paquette, L., Kida, T. 1988. The Effect of Decision Strategy and Task Complexity on 
Decision Performance. Organizational Behavior and Human Decision Processes, 41 (February), 128-142.

Park, C. W., Mothersbaugh, D.L., Feick, L. 1994. Consumer Knowledge Assessment. Journal of Consumer Research, 21(June), 71-82.

Parsons, T. 1951. The Social System, New York, Free Press.

--- 1967. Sociological Theory and Modern Society, New York, Free Press.

Paulssen, M., Roulet, R., Wilke, S. 2011. Risk as moderator of the trust-loyalty relationship. European Journal of Marketing, 48(5/6), 964-981.

Payne, J.W. 1982. Contingent Decision Behavior. Psychological Bulletin, 112 (September), $382-402$.

Perry, V. G., Morris, M.D. 2005. Who Is in Control? The Role of Self-Perception, Knowledge, and Income in Explaining Consumer Financial Behavior. The Journal of Consumer Affairs, 39(2), 299-313.

Pillai, K.G., Goldsmith, R.E. 2006. Calibrating Managerial Knowledge of Customer Feedback Measures: a Conceptual Model. Marketing Theory, 6 (June), 223-243.

---, --- and Hofacker, C. 2007. Calibration of Consumer Knowledge of the Web. International Journal of Research in Marketing, 24 (September), 254-267.

Ramani, G., Kumar, V. 2008. Interaction Orientation and Firm Performance. Journal of Marketing, 72(January), 27-45.

Reeh, K.L. 2007. En kvalitativ undersøgelse af fattigdom i Odense Kommune. Center for Anvendt Sundhedstjenesteforskning og Teknologivurdering, August, 40 pages.

Regó, L.L., Morgan, N.A., Fornell, C. 2013. Reexamining the Market Share-Customer Satisfaction Relationship, Journal of Marketing, 27(September), 1-20.

Roth, F. 2009. Does Too Much Trust Hamper Economic Growth?, Kyklos, 62(1), 103-128. 
Rotfeld, H.J. 2008. Financial Aliteracy. Journal of Consumer Affairs, 42(2), 306-309.

Ryu, G., Park J., Feick, L. 2006. The Role of Product Type and Country-of-Origin in Decisions about Choice of Endorser Ethnicity in Advertising. Psychology \& Marketing, 23(6), 487-513.

Sapienza, P., Zingales, L. 2012. A Trust Crisis. International Review of Finance, 12(2), 123131.

Scott, R.W. 2004. Institutional theory. In: Encyclopedia of Social Theory, G. Ritzer, ed. Thousand Oaks, CA: Sage, 408-414.

Selnes, F., Sallis, J. 2003. Promoting Relationship Learning, Journal of Marketing, 67(July), $80-95$.

Sevim, N., Temizel, F., Sayilir, Ö. 2012. The effects of financial literacy on the borrowing behaviour of Turkish financial consumers," International Journal of Consumer Studies, 36(5), 573-579.

Shiu, E.M.K., Walsh, G., Hassan, L.M., Shaw, D. 2011. Consumer Uncertainty, Revisited. Psychology \& Marketing, 28(6), 584-607.

Sirdeshmukh, D., Singh, J., Sabol, B. 2002. Consumer trust, value and loyalty in relational exchanges. Journal of Marketing, 66(1), 15-37.

Taylor, A R. 2009. Perceived Effort Saved's Influence on Perceptions of Effort and Accuracy. Journal of Behavioral Studies in Business, 1(July), 1-18.

Tax, S.S., Brown, S.W., Chandrashekaran, D. 1998. Customer Evaluations of Service Complaint Experiences: Implications for Relationship Marketing. Journal of Marketing, 62(April), 60-76.

Todd, P.M., Benbasat, I. 1994. The Influence of Decision Aids on Choice Strategies: An Experimental Analysis of the Role of Cognitive Effort. Organizational Behavior and Human Decision Processes, 60, 36-74. 
Tomlinson, E.C., Mayer, R.C. 2009. The Role of Causal Attribution Dimensions in Trust Repair. Academy of Management Review, 34(1), 85-104.

Towers Perrin 2008. Financial Literacy and Transparency Initiatives and Tools in Life and Pensions, DIA Report 2008:6, 115 pages.

Vallaster, C., A. Lindgreen, and F. Maon 2012. Strategically Leveraging Corporate Social Responsibility: A Corporate Branding Perspective. California Management Review, 54(3), 1-27.

Weiner B. 1985. An attributional theory of achievement motivation and emotion. Psychological Review, 4, 548-573.

Weiner, B. 1986. An attributional model of motivation and emotion. New York: Springer Verlag.

Workman, J.P. Jr., Homburg, C., Jensen, O. 2003. Intraorganizational Determinants of Key Account Management Effectiveness. Journal of the Academy of Marketing Science, $31(1), 3-21$.

Yates, D. and Ward, C. 2012. Are Your Personal Financial Characteristics Healthy? Journal of Business and Economics Research, 10(4), 225-232.

Ye, J., Marinova, D., Singh, J. 2007. Strategic change implementation and performance loss in the front lines. Journal of Marketing, 71(4), 156-171.

Zak, P. and Knack, S. 2001. Trust and growth. The Economic Journal, 111(April), 295-321. 
Table 1

Confirmatory Factor Analysis Results

\begin{tabular}{lcccc}
\hline Construct/indicator & $\begin{array}{l}\text { Standardized } \\
\text { factor loading }^{\mathrm{a}}\end{array}$ & $\begin{array}{l}\text { Critical } \\
\text { ratio }\end{array}$ & $\begin{array}{c}\text { Composite } \\
\text { reliability }\end{array}$ & $\begin{array}{l}\text { Extracted } \\
\text { variance }\end{array}$ \\
\hline Broad-scope trust (BST) & & & & .51 \\
X1 & .60 & - & .80 & \\
X2 & .67 & 16.59 & & \\
X3 & .74 & 17.81 & & \\
X4 & .83 & 18.22 & & .51 \\
Knowledge & & & & \\
X5 & .63 & - & .83 & \\
X6 & .66 & 15.36 & & \\
X7 & .75 & 17.64 & & \\
X8 & .74 & 17.71 & & \\
X9 & .77 & 19.86 & & \\
Cognitive effort & & & .79 & \\
X10 & .80 & - & & \\
X11 & .76 & 28.18 & & \\
X12 & .69 & 26.73 & & \\
Financial healthiness & & & .86 & \\
X13 & .67 & - & & \\
X14 & .72 & 22.68 & & \\
X15 & .80 & 23.91 & & \\
X16 & .70 & 21.99 & & \\
X17 & .67 & 21.55 & & \\
X18 & .69 & 22.09 & & \\
Financial involvement (control & & & & \\
variable) & & & & \\
X19 & .82 & -82 & \\
X20 & .75 & 31.32 & & \\
X21 & .54 & 19.70 & & \\
X22 & & 32.04 & & \\
& & & & \\
\hline
\end{tabular}

${ }^{\text {a }}$ One item for each construct was set to 1 .

Model fit: $\chi^{2}=724.52$ (d.f.=199, $p<.01$ ); CFI=.94; NFI=.93; RMSEA=.050; Hoelter(0.05)=455. 
Table 2

Correlations and Descriptive Statistics

\begin{tabular}{lccccc}
\hline & 1 & 2 & 3 & 4 & 5 \\
\hline 1. Broad-scope trust (BST) & 1.00 & $.40^{\mathrm{a}}$ & .02 & $.18^{\mathrm{a}}$ & $.43^{\mathrm{a}}$ \\
2. Knowledge & $.44^{\mathrm{a}}$ & 1.00 & .01 & $.18^{\mathrm{a}}$ & $.27^{\mathrm{a}}$ \\
3. Cognitive effort & -.07 & .06 & 1.00 & .02 & $.24^{\mathrm{a}}$ \\
4. Financial healthiness & $.23^{\mathrm{a}}$ & $.23^{\mathrm{a}}$ & .08 & 1.00 & $.18^{\mathrm{a}}$ \\
5. Financial Involvement (control) & $.43^{\mathrm{a}}$ & $.27^{\mathrm{a}}$ & $.24^{\mathrm{a}}$ & $.19^{\mathrm{a}}$ & 1.00 \\
Online search (CMV marker) & .06 & .08 & $-.09^{\mathrm{b}}$ & -.02 & -.01 \\
Mean & 5.00 & $5.30^{*}$ & 2.72 & 5.41 & 4.59 \\
Std. deviation & 1.31 & 1.17 & 1.40 & 1.43 & 1.29 \\
\hline
\end{tabular}

${ }_{p}^{\mathrm{a}}<.01 ;{ }^{\mathrm{b}} p<.05$.

Notes: Correlations adjusted for common method bias are reported above the diagonal; zero-order correlations are reported below the diagonal. $\mathrm{CMV}=$ common method variance.

Averaged scale means are reported; all items were measured on 7-point Likert scales.

*The mean value reported is based on the three subjective knowledge items; the average value of the objective knowledge item (ranging from 1 to 11 ) was 7.59 (std.deviation=1.75). 
Table 3

Estimated Coefficients for the Influence of Broad-scope trust on Knowledge, Cognitive Effort, and Financial Healthiness

\begin{tabular}{|c|c|c|c|c|c|c|c|c|}
\hline \multirow[b]{3}{*}{ Independent Constructs } & \multicolumn{4}{|c|}{$\begin{array}{c}\text { Bank Services } \\
\text { Dependent Constructs }\end{array}$} & \multicolumn{4}{|c|}{$\begin{array}{c}\text { Mutual Fund Services } \\
\text { Dependent Constructs }\end{array}$} \\
\hline & \multicolumn{2}{|c|}{ Cognitive effort } & \multicolumn{2}{|c|}{$\underline{\text { Financial healthiness }}$} & \multicolumn{2}{|c|}{ Cognitive effort } & \multicolumn{2}{|c|}{ Financial healthiness } \\
\hline & $\beta(\mathrm{SE}) \quad t-$ & $t-$ Value & $\beta(\mathrm{SE}) \quad t$ & $t$-Value & $\beta(\mathrm{SE}) \quad t$ & $t$-Value & $\beta(\mathrm{SE})$ & $t$-Value \\
\hline \multicolumn{9}{|c|}{ KCFB Baseline Model Relationships } \\
\hline Knowledge & $.14(.05)$ & $2.90^{\mathrm{a}}$ & $.20(.06)$ & $4.16^{\mathrm{a}}$ & $.14(.05)$ & $2.81^{\mathrm{a}}$ & $.20(.05)$ & $4.22^{\mathrm{a}}$ \\
\hline Cognitive effort & -- & - & $.10(.04)$ & $2.78^{\mathrm{a}}$ & -- & - & $.10(.04)$ & $2.78^{\mathrm{a}}$ \\
\hline Broad-scope trust (BST) & $-.09(.04)$ & $-2.04^{b}$ & $.21(.04)$ & $4.46^{\mathrm{a}}$ & $-.09(.04)$ & $-2.06^{\mathrm{b}}$ & $.20(.04)$ & $4.66^{\mathrm{a}}$ \\
\hline \multicolumn{9}{|c|}{ Hypothesized Model Relationships } \\
\hline Knowledge x BST & $-.05(.06)$ & -.99 & $-.12(.07)$ & $-2.00^{\mathrm{b}}$ & $-.07(.07)$ & -1.30 & $-.14(.07)$ & $-2.06^{\mathrm{b}}$ \\
\hline Cognitive effort x BST & -- & - & $-.12(.05)$ & $-2.04^{b}$ & -- & - & $-.11(.05)$ & $-1.97^{\mathrm{b}}$ \\
\hline \multicolumn{9}{|l|}{ Control Variables } \\
\hline Financial involvement & $.18(.05)$ & $3.66^{\mathrm{a}}$ & $.07(.04)$ & 1.71 & $.18(.05)$ & $3.68^{\mathrm{a}}$ & $.10(.04)$ & $2.08^{b}$ \\
\hline Income & $.07(.02)$ & $2.01^{\mathrm{b}}$ & $.18(.02)$ & $5.38^{\mathrm{a}}$ & $.02(.03)$ & .50 & $.22(.03)$ & $5.54^{\mathrm{a}}$ \\
\hline Education & $.01(.03)$ & .26 & $.02(.02)$ & .74 & $.06(.03)$ & 1.56 & $.02(.02)$ & .69 \\
\hline
\end{tabular}

Notes ${ }^{a}$ Significant on the $1 \%$ level; ${ }^{b}$ significant on the $5 \%$ level. Model fit: $\chi^{2}=6180.55$ (d.f. $=2383, p<.01$ ); CFI=.92; NFI=.90; RMSEA=.076; NNFI=.90. $\mathrm{R}^{2}$ (Cognitive effort): Bank services $=.05$, mutual fund services $=.05$.

$\mathrm{R}^{2}$ (Financial healthiness): Bank services $=.14$, mutual fund services $=.11$. 
Fig. 1

Conceptual Model used to investigate the Moderating Effects of Broad-scope trust on Knowledge, Cognitive Effort, and Financial Healthiness

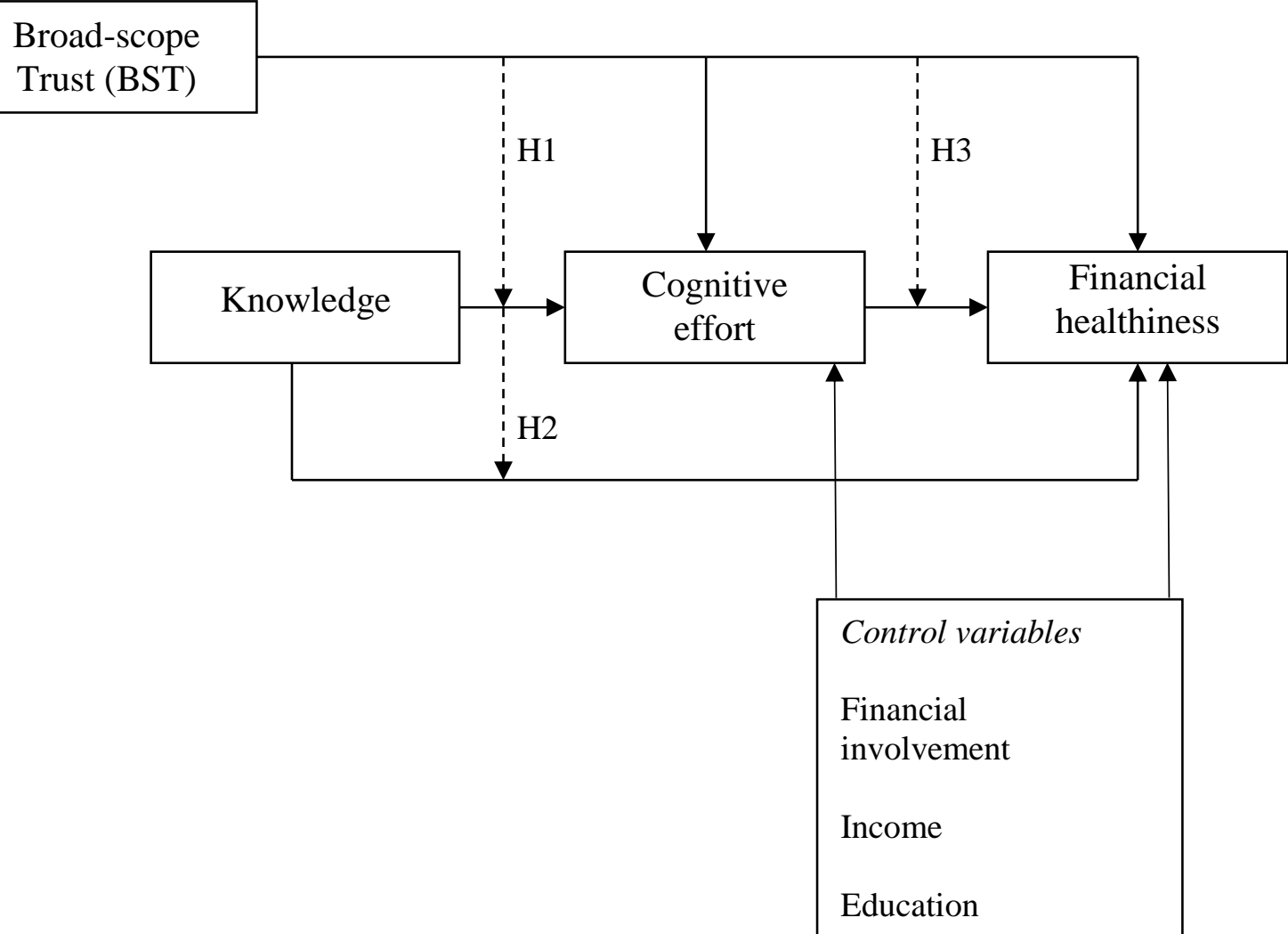

Notes

KCF model = relationships between knowledge, cognitive effort, and financial healthiness .

Direct effects (baseline model effects)

Moderating effects (hypothesized effects) 
Fig. 2

Interaction between Knowledge and Broad-scope trust (BST)

Panel a: Bank services.

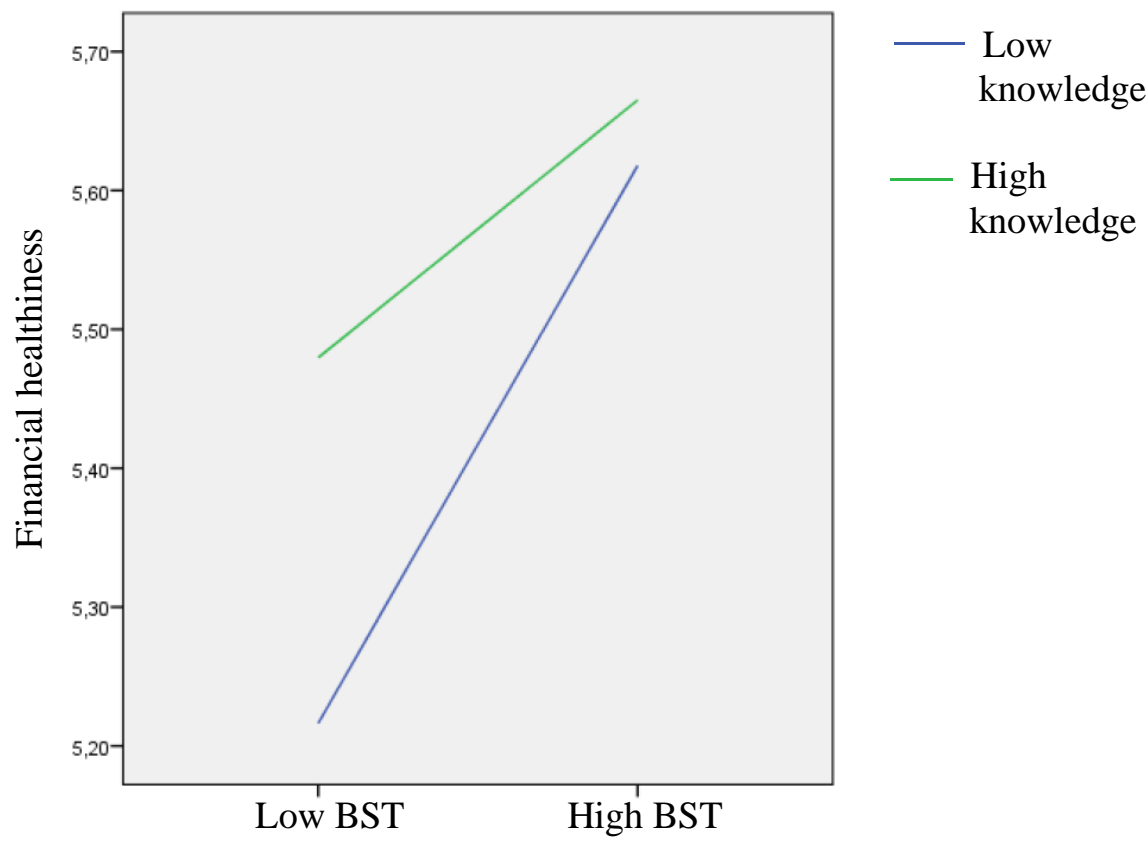

Panel b: Mutual fund services.

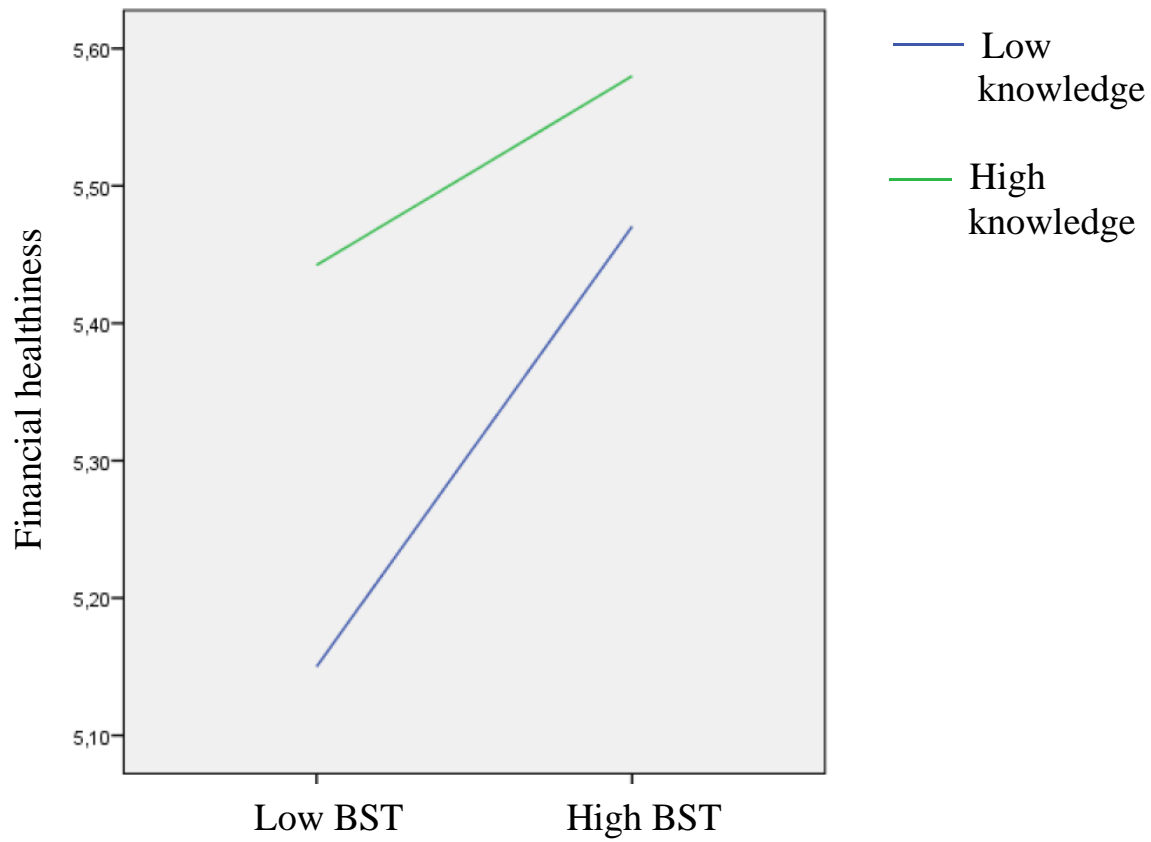

Note: Median splits created the 'low BST versus high BST' and the 'low knowledge versus high knowledge' groups, respectively. 
Fig. 3

Interaction between Cognitive Effort and Broad-scope trust (BST)

Panel a: Bank services.

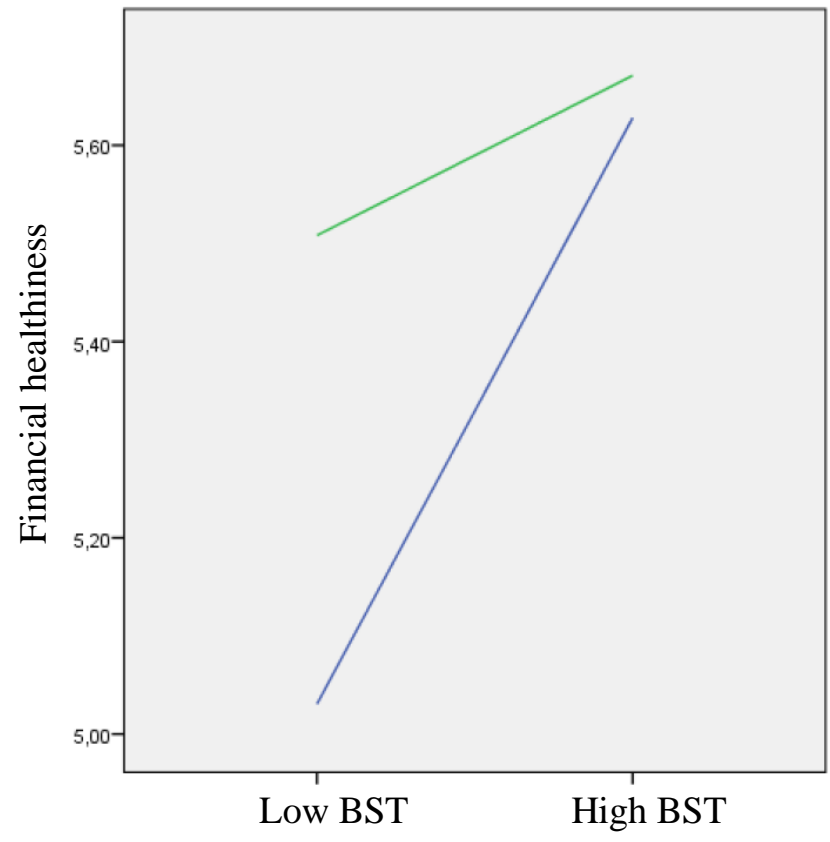

Low cognitive effort

- High cognitive effort

Panel b: Mutual fund services.

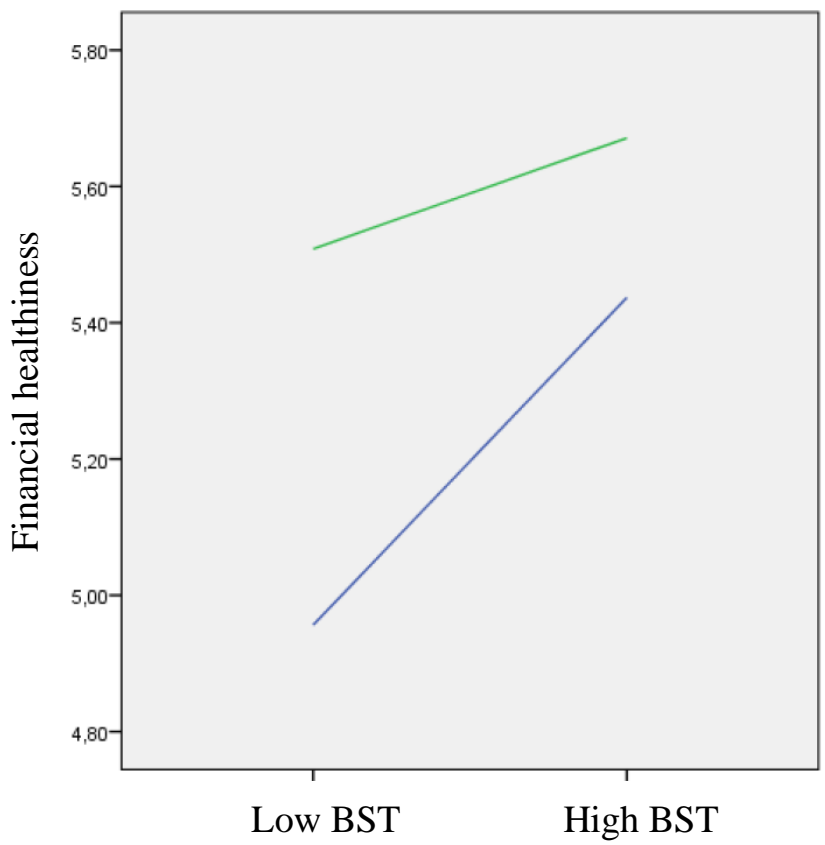

Low cognitive effort

- High cognitive effort

Note: Median splits created the 'low BST versus high BST' and the 'low cognitive effort versus high cognitive effort' groups, respectively. 


\section{Appendix}

Items used to measure the constructs in the study

\section{Broad-scope trust (BST)}

$\mathrm{X} 1$. In general, I believe that financial companies cannot be relied on to keep their promises*

$\mathrm{X} 2$. In general, I believe that financial companies are trustworthy

X3. In general, I find it necessary to be cautious when dealing with financial companies*

$\mathrm{X} 4$. Overall, I believe financial companies are honest

\section{Knowledge (subjective) $)^{\mathrm{a}}$}

X5. In general, how knowledgeable are you about different types of [the service in question] in the market?

X6. In general, how much experience do you have with different types of [the service in question] in the market?

X7. Compared to others you know, how knowledgeable are you about the features of different [the service in question] in the market?

X8. For each of the objective knowledge items shown below - see 'knowledge (objective)' - respondents were asked to indicate their confidence (subjective knowledge) that the answer was correct.

\section{Knowledge (objective) $)^{\mathrm{a}}$}

X9.

General objective knowledge items

Annual Percentage Rate (APR) is an overall indication of how much you pay on a loan only from the perspective of the establishment costs and commission fees.

It is only when you acquire a service elsewhere than in banks or mutual fund companies that you as a consumer is entitled to get the APR.

Everyone who advertises prices on loans must disclose the APR in their publicly available materials.

Peter is considering creating an overdraft of $\$ 5,000$ or $\$ 10,000$ with an interest rate of $5 \%$ in a bank. There is no fee to set up the bank credit, and no ongoing management fee. Peter gets the lowest APR on the loan for $\$ 10,000$.

APR summarizes the annual interest costs and fees in one figure so that you have the opportunity to compare the annual cost of acquiring different financial services of the same type with the same maturity.

APR may not be used to compare the cost of various loans of the same type with the same maturity.

Objective knowledge items (bank industry)

In general, it is normally more expensive to finance products such as a flat-screen TV via the credit agreements that a television store may typically offer than to finance it through a loan that you get in a bank.

An interest rate of $2.5 \%$ per year on a bank account is currently the highest deposit rate on an ordinary bank account that you can get at any bank or savings bank in [the country under consideration].

Fees and commissions on loans with a maturity of less than two years are tax deductible.

Peter, who works full time and therefore pay taxes, gets $2.25 \%$ interest on his bank account. If inflation is $2 \%$, then Peter make money by having money in his bank account.

Objective knowledge items (mutual fund industry)

Mutual funds are an alternative to investing directly in bonds and equities.

Only few mutual funds investors have their investment certificates registered in a repository.

When investing in mutual funds you can always be $100 \%$ sure that you will get a fixed interest rate.

If you buy one mutual fund certificate out of, for instance, one hundred certificates issued by a mutual fund it means that you own one per cent of that mutual fund's fortune.

\section{Cognitive effort}

X10. I put a lot of effort into making the decision

X11. I thought very hard about which product to choose

X12. I didn't pay much attention while making the choice* 
Financial healthiness (behaviour over the last year)

$\mathrm{X} 13$. I set money aside for savings.

X14. I reached the maximum limit on a credit card.*

X15. I spent more money than I had.*

X16. I had to cut living expenses.*

X17. I had to buy on credit.*

X18. I had financial troubles because I did not have enough money.*

Financial involvement (control variable)

X19. Financial services matters a great deal to me

$\mathrm{X} 20$. Financial services are very relevant to me

$\mathrm{X} 21$. Financial services are very important to me

X22. I care a lot about financial services.

Propensity to use the web when searching for financial information (CMV-marker)

CMV1. When searching for financial information in general

CMV2. When searching for financial information relating to pre-specified financial services

CMV3. When searching for information that compares financial services

Notes

*Item reverse coded.

${ }^{a}$ Because of a high degree of internal consistency the objective and subjective knowledge measures were combined into one single knowledge measure in the study.

Please note that the items measuring objective knowledge take into account the financial regulations, etc. existing in the country in which the surveys were conducted. Some of the items may need to be modified in order to be applicable for studies in other countries.

All items were measured on 7-point Likert scales (1=strongly disagree; $7=$ strongly agree) with the exception of objective knowledge. 